\title{
An Update in Antimicrobial Therapies and Infection Prevention in Pediatric Lung Transplant Recipients
}

\author{
O. C. Smibert ${ }^{1} \cdot$ M. A. Paraskeva ${ }^{2} \cdot$ G. Westall ${ }^{2} \cdot$ Greg Snell $^{2}$
}

Published online: 6 September 2018

C) Springer Nature Switzerland AG 2018

\begin{abstract}
Lung transplantation can offer life-prolonging therapy to children with otherwise terminal end-stage lung disease. However, infectious complications, like those experienced by their adult counterparts, are a significant cause of morbidity and mortality. These include bacteria, viruses, and fungi that infect the patient pretransplant and those that may be acquired from the donor or by the recipient in the months to years posttransplant. An understanding of the approach to the management of each potential infecting organism is required to ensure optimal outcomes. In particular, emphasis on aggressive preoperative management of infections in pediatric patients with cystic fibrosis is important. These include multidrug-resistant Gram-negative bacteria, fungi, and Mycobacterium abscessus, the posttransplant outcome of which depends on optimal pretransplant management, including vaccination and other preventive, antibiotic-sparing strategies. Similarly, increasing the transplant donor pool to meet rising transplant demands is an issue of critical importance. Expanded-criteria donorsthose at increased risk of blood-borne viruses in particular-are increasingly being considered and transplants undertaken to meet the rising demand. There is growing evidence in the adult pool that these transplants are safe and associated with comparable outcomes. Pediatric transplanters are therefore likely to be presented with increased-risk donors for their patients. Finally, numerous novel antibiotic-sparing therapeutic approaches are on the horizon to help combat infections that currently compromise transplant outcomes.
\end{abstract}

\section{Key Points}

Despite advances in surgical techniques and optimization of non-infectious complications after lung transplant, infectious morbidity and mortality rates remain high.

Novel antibacterial/antiviral-sparing approaches to the management of infection are likely to become an increasingly important component of therapy in the future in light of rising rates of bacterial and viral resistance.

Expansion of the lung donor pool to include donors with potential or actual blood-borne viral infections is increasingly likely.

Greg Snell

G.Snell@alfred.org.au

1 Department of Infectious Diseases, The Alfred Hospital and Monash University, Melbourne, VIC 3004, Australia

2 Department of Lung Transplant Service, The Alfred Hospital and Monash University, 55 Commercial Road, Melbourne, VIC 3004, Australia

\section{Introduction}

Lung transplantation (LTx) offers life-prolonging therapy to children with end-stage lung diseases [1]. According to the International Society for Heart and Lung Transplant data registry, upwards of 961 pediatric recipients underwent LTx between 2008 and 2016 [2]. The majority (> 70\%) of these recipients were aged between 11 and 17 years, and $>50 \%$ received a deceased organ from an adult donor, making them as vulnerable to donor-derived infections as their adult counterparts [2]. The most frequent indication for LTx in this setting is cystic fibrosis (CF), which accounts for $>66 \%$ of cases [2]. These children are often unwell, with complicated infections associated with multidrug-resistant organisms at the time of transplant. After LTx, these children are at risk of dissemination of existing commensals and infecting agents as well as the acquisition of new infections. Notably, all infections are difficult to treat in the post-LTx setting because of the combination of immune-suppressing agents and complex drug-drug interactions.

Aggressive peri-transplant infection-management strategies are a critical part of successful clinical LTx outcomes. 
Timely planning is required to target peri-LTx eradication with a combination of surgical debridement and directed antimicrobial and antiviral therapies. Such approaches must be based on knowledge of both donor and recipient pathogens-previous, current, and predicted. Antimicrobialsparing strategies, including vaccination and novel adjunctive therapies, are also increasingly recognized as important components of effective models of care, a discussion of which is included in this review.

There are numerous organisms and therapies considered of particular interest to pediatric LTx recipients as well as recent novel insights into the management of specific pathogens. This review summarizes the recent literature on these topics.

\section{Bacterial Infections}

\subsection{Mycoplasma and Ureaplasma Species}

Mycoplasma hominis and Ureaplasma spp. make up part of the genitourinary commensal flora in up to $80 \%$ of young, sexually active adults $[3,4]$. While not recognized as part of the normal lower respiratory tract flora, up to $8 \%$ of adults with chronic respiratory disease and $14 \%$ of young adult LTx donors have been found to harbor these organisms in the lower respiratory tract [5]. In children, Ureaplasma spp. have been associated with wheezing and pertussis-like syndromes, urinary tract infections, various arthritides, and fatal pneumonitis, whereas $M$. hominis is associated with urinary tract, surgical site, skin, and soft tissue infections and dissemination with overwhelming infection in the immunocompromised host [6-12]. The number of reports of these organisms causing disease after LTx is increasing and, because they are difficult to diagnose, it is likely these cases are under recognized in both adult and pediatric transplant populations [13, 14]. In addition, posttransplant hyperammonemia syndrome, an increasingly recognized cause of morbidity and mortality early posttransplant appears to be closely associated with infection with these organisms [5].

The genital mycoplasma, as they are often referred to, are the smallest self-replicating organisms [15]. They lack a cell wall, which means they do not take up conventional bacterial stains in the laboratory and will not be detected by Gram stain [15]. Many are uncultivable on conventional agar, but those that are form microscopic pinpoint colonies, often obscured by competing bacterial flora so may be overlooked and missed by laboratory staff. Infection should be considered when microbiological samples demonstrate purulence but no organism is identified on Gram stain in the setting of a clinically compatible syndrome. These organisms are extremely sensitive and often will not survive the collection of clinical specimens [13]. Specimens should be inoculated at the bedside whenever possible, ideally using liquid media, and transported to the laboratory for inoculation within $60 \mathrm{~min}$ to improve diagnostic yield [13]. Cotton swabs should be avoided for sampling areas suspicious for infection as they can inhibit growth of the organism [15]. Real-time polymerase chain reaction (PCR)-based tests provide highly accurate and rapid results, and numerous platforms are commercially available [16]. Molecular testing is typically only available at reference or specialized laboratories. The advantage of molecular diagnostics is detection of nonviable organisms missed with culture methods $[15,17]$. Notwithstanding all this, no validated data exist to link PCR results to disseminated disease.

The lack of cell wall in these organisms has not only diagnostic implications but also therapeutic consequences. The bacteria are non-susceptible to cell wall-active antibiotics and are considered inherently resistant to beta-lactams, glycopeptides, sulphonamides, trimethoprim, and rifampin [15]. Therefore, the antibiotics routinely administered by most institutions to their unwell and undifferentiated LTx recipients, typically beta-lactam/beta-lactamase combinations or carbapenems, will be ineffective against these bacteria. Infection should therefore also be considered in patients who do not respond to these empiric regimens. Resistance to macrolides and lincosamides varies according to species [13]. Tetracycline resistance has been well documented in M. hominis and Ureaplasma spp., with rates approaching $40-50 \%$, mediated by the tetM determinant [18]. Rates of high-level macrolide resistance are increasing [19]. Fluoroquinolones such as moxifloxacin and levofloxacin are usually active against all the genital mycoplasma species [15]. Reports describing emergence of resistance with singleagent therapy in overwhelming infection leads the authors to recommend empirical dual-agent therapy in LTx recipients with disseminated infection while awaiting either in vitro or molecular evidence to support directed therapy [20].

Infection typically occurs within the first 1-2 weeks postLTx $[5,13,14,21,22]$. The most frequent presentations are pleuro-pericardial and sternal or wound infections, with bacteremia occurring less frequently [14, 21-23]. While only a single case has been reported in the pediatric LTx literature, it is likely that cases go unrecognised. Dixit et al. [10] described a bilateral LTx recipient with a history of stem cell transplant who developed fevers, pleural effusions, and respiratory distress requiring reintubation day 5 post-LTx after a favorable early post-LTx course. This case closely resembles those reported in the adult population.

The origin of infection in these patients remains unclear, with debate surrounding whether infection represents translocation of recipient flora versus donor-derived infection. There is increasing evidence to support donor-derived transmission as the primary route of acquisition. Fernandez et al. [5] undertook screening urine and bronchoalveolar lavage 
(BAL) in a cohort of 29 consecutive LTx recipients and their 28 donors and found that $14 \%$ of donor BALs were positive for either Ureaplasma spp. or M. hominis, whereas only a single recipient had a positive baseline test with isolation from urine. Importantly, all recipients who received lungs with a BAL detecting a genital mycoplasma went on to develop pulmonary infiltrates [5]. Furthermore, there was a positive association between donor isolation of genital mycoplasma and younger donor age, a greater number of donor sexual partners, and donor male sex. The authors of this review used whole genome sequencing to demonstrate that $M$. hominis was the cause of donor-derived infection in an adult LTx recipient, and various other reports have demonstrated donor colonization with subsequent recipient infection $[13,14]$.

Hyperammonemia has historically been a poorly understood and potentially fatal complication post-LTx. Calcineurin inhibitors (CNIs) have long been implicated as a contributor to the development of hyperammonemia, as all case reports have involved cyclosporine- or tacrolimus-based regimens [24]. Understanding of this entity has recently progressed, with reports proposing a causal relationship between Ureaplasma spp. infection and hyperammonemia $[20,25]$. Previous approaches to treatment included aggressive ammonia-lowering therapies and cessation of the CNI. However, administration of antimicrobials directed at Ureaplasma spp. infection has recently been shown to result in complete clinical resolution and should be part of therapy in all patients [20]. Although understanding has progressed, the etiology is again largely unknown, and understanding has been limited to case reports and small series [24, 26, 27]. Chen et al. [28] recently published the largest case series to date and developed a treatment protocol from their experience, recommending empirical genital mycoplasma-directed antibacterials pending microbiological study results. Until further evidence regarding the pathophysiology of hyperammonemia is provided, we recommend dual empirical genital mycoplasma-directed therapy while awaiting genital mycoplasma antimicrobial susceptibility testing, in addition to the protocol outlined by Chen et al. [28].

In summary, disseminated infection with genital mycoplasmas post-LTx likely occurs more frequently than currently recognized. A high index of suspicion is required because these organisms are difficult to isolate with conventional methods. These organisms are capable of causing sternal wound, pleuro-pericardial, and disseminated infections in addition to the often fatal hyperammonemia syndrome.

\subsection{Mycobacterium abscessus Complex}

Mycobacterium abscessus complex (MA) has emerged as one of the most problematic infections post-LTx, mainly because of its refractoriness to treatment [29-31]. While pretransplant infection is largely confined to the respiratory tract, post-LTx infection is more likely to be extrapulmonary and disseminated and very difficult to treat $[32,33]$. While MA was historically thought to be an absolute contraindication to LTx, increasing evidence from institutional cohorts indicates that outcomes in recipients with pre-LTx MA are comparable to those of their uninfected counterparts, particularly those with aggressive pre-LTx management [34-36]. The incidence and prevalence of nontuberculous mycobacteria, including MA, continues to rise in children with CF, the foremost indication for pediatric LTx, so both transplant physicians and CF physicians must work together to optimize the pre- and peri-LTx management of these infections to optimize post-LTx outcomes [37-39].

Since its elevation to species level, MA has been further divided into three subspecies using 16S ribosomal RNA gene sequencing: M. abscessus subsp. abscessus (MAA), $M$. abscessus subsp. bolletii (MAB), and M. abscessus subsp. massiliense (MAM). Based on sequencing of the erm(41) gene, suggestions have been made that further subdivision is necessary [40, 41]. Identification to subspecies is now a critical component of evaluating any patient with an MA, as significant therapeutic and prognostic predictions can be made based on identification of subspecies alone [41-47].

MA is ubiquitous in the environment, particularly in water sources, and outbreaks have been traced to environmental sources and devices contaminated with tap water [48]. MA has been shown to persist in the environment after exposure to numerous hospital biocides, and concern has arisen that transmission between patients may occur via contaminated fomites [49]. However, investigations of single-institution outbreaks have failed to demonstrate environmental sources beyond contaminated water reservoirs [29, 50, 51]. Guidelines from the American Thoracic Society/Infectious Diseases Society of America suggest avoiding contamination of indwelling intravenous catheters with tap water and the use of tap water in fiberoptic endoscopic cleaning processes to avoid contamination with nontuberculous mycobacteria, but there remain no clear guidelines regarding the utility of patient isolation or other infectionprevention measures. Recently, MA has been demonstrated to survive in respirable-size aerosol droplets that can travel up to $4 \mathrm{~m}$, thus providing proof of concept for risk of patientto-patient transmission [52]. However, the investigation of outbreaks using molecular diagnostics have yielded contradictory results with regards to transmissibility between patients, with evidence both in favor of and against crosstransmission. There is some suggestion that transmission risk may be subspecies dependent, with MAM a greater risk than MAA or MAB $[29,53]$. In the absence of definitive data documenting patient-to-patient spread, isolation practices are CF and transplant center dependent [54]. Further evidence is required to direct infection-control policies, but 
the authors suggest that centers have some form of infectioncontrol/separation policies in place for patients with MA, particularly those with smear-positive respiratory disease.

MA is an intrinsically multidrug-resistant organism. The most data exist for clarithromycin resistance, which may be intrinsic or acquired, mediated by the erm(41) gene and $r r l$ gene, respectively. The patterns of resistance can be somewhat predicted based on subspecies. MAB have a complete erm(41) gene associated with clarithromycin resistance, whereas nearly all MAM harbor non-functional erm(41) genes that render them intrinsically susceptible to clarithromycin, and MAA have a complete erm(41) gene and sequevars associated with both clarithromycin susceptibility or resistance [40, 42]. There is increasing evidence that an even more complex overlapping network of resistance mechanisms are at play that includes, among others, amikacin resistance mediated by the rrs gene [55]. Most recently, identification of whiB7, a transcriptional activator, induced by exposure to antibiotics and conserved across all species of mycobacteria, has been described [56, 57]. The induction of whiB7-mediated resistance induced by one antibiotic inducer can promote cross-resistance to additional antibiotics [56, 57]. This implies that one group of antibiotics may antagonize the effects of another, for example that clarithromycin can antagonize the efficacy of amikacin. The practical implications of this finding are unclear but suggest that sequential antibiotic therapy based on inducers and antagonizers of this pathway may theoretically present a viable alternative to the existing approach that consists of multiple antibiotics administered concurrently.

Because there is poor correlation between in vitro antibiotic susceptibility testing and in vivo efficacy, increasing hope had been placed on the development of commercial molecular assays to identify these molecular markers of resistance [56]. Unfortunately, however, reports of the positive correlation between genotypic and phenotypic testing for resistance have been conflicting [55, 58, 59]. Furthermore, significant variations in genotypic and phenotypic resistance patterns have been observed based on geography [55]. For this reason, the authors recommend that all centers continue to routinely undertake MA antibiotic susceptibility testing and utilize local data regarding resistance patterns in addition to any available molecular diagnostics.

Current guidelines for treatment of MA emphasize the need for combination therapy, typically with a macrolide backbone in addition to amikacin and cefoxitin/imipenem for an extended treatment course, typically months to years in duration [60]. Unfortunately, treatment in the immunocompromized, including LTx recipients, can be even more complicated, required for longer durations (occasionally indefinitely), and associated with significant toxicity and development of resistance. Given the average rate of eradication is only $45 \%$ for these infections, focus has been directed at identifying novel approaches to improve outcomes. In two cases recently described by Scott et al. [61], two patients with CF (including a child aged 10 years) with smear-positive lower respiratory tract infection were treated with aerosolized granulocyte-macrophage colonystimulating factor (GM-CSF), one as sole therapy and the other as an adjunctive therapy in the setting of a failing multidrug regimen. Both patients experienced sputum conversion without toxicity [61]. The authors hypothesized that abnormally low levels of GM-CSF in the airways of patients with CF predispose them to persistent infection. This therapy may be most useful in the pre-LTx setting to improve the chance of sputum smear and culture conversion, which has been associated with better post-LTx outcomes [31].

An Ambler class A $\beta$-lactamase $\left(\mathrm{Bla}_{\mathrm{Mab}}\right)$ was recently identified in MA, with hope that a $\beta$-lactam $\beta$-lactamase inhibitor combination might provide an additional antimycobacterial to add to the current armamentarium [62]. While Bla $\mathrm{Mab}_{\mathrm{ab}}$ is not inhibited by clavulanate, sulbactam, or tazobactam, a combination of avibactam with carbapenems and ceftaroline has improved efficacy in vivo [62-65]. Human data are currently lacking, but this discovery provides hope for clinicians treating these recalcitrant infections.

An interesting observation was made during in vitro studies of antimycobacterial effectiveness when synergism between different classes of antibiotics was identified. Zhang et al. [66] showed that the combination of clarithromycin and moxifloxacin or clarithromycin and tigecycline demonstrated greater synergism in MAM than in MAA. The same group went on to demonstrate that the combination of linezolid + amikacin and of linezolid + tigecycline also demonstrated synergism, in contrast to linezolid + cefoxitin or moxifloxacin, which demonstrated antagonism [67]. The future approach to therapy for MA may well consist of a combination of these recent observations to include sequential antimycobacterials to capitalize on synergism and avoid antagonisms between classes, in addition to adjunctive nonantibacterial-based therapies such as inhaled GM-CSF.

Despite recent advances, MA remains an extremely challenging organism to treat, presenting a particular problem in those with CF and leading into the post-LTx setting. Emphasis must be placed on a carefully constructed periLTx diagnostic and therapeutic management plan to ensure successful post-LTx outcomes. Extended sensitivity testing and aggressive antimycobacterial therapies (including intra- and post-LTx surgical strategies, reduced immunosuppression, and long-term MA surveillance) must be part of a multidisciplinary and long-term approach to treatment for this recalcitrant organism. 


\subsection{Resistant Gram-Negative Bacteria}

Multidrug-resistant Gram-negative (MDR GN) infections and colonization present a particular challenge in patients with CF, the most frequent indication for pediatric LTx, and remain problematic post-LTx [68-71], with a negative impact on survival $[68,72,73]$. Children pediatric recipients are increasingly likely to be offered otherwise viable lungs from donors with MDR GN infections, particularly in the pool of donors recently hospitalized or even simply living in the countries with very high rates of drug resistance [74]. Recipient outcomes in this setting appear to be related to appropriate peri-transplant management with targeted antimicrobials, highlighting the need for communication between transplant coordinators, the microbiology laboratory, transplant clinicians, and infectious diseases clinicians $[68,75]$. Numerous newer $\beta$-lactam- and carbapenem$\beta$-lactamase inhibitor combinations have recently become available, with emerging evidence in the adult population that these agents will be safe, well-tolerated, and efficacious. The combination of ceftazidime/avibactam has been shown to improve the inhibitory activity of ceftazidime towards Gram negatives producing class A, C, and some class D $\beta$-lactamases, with a particular affinity for difficult-to-treat Klebsiella pneumoniae carbapenemase (KPC)-producing Gram negatives [76-79]. Emerging data suggest this combination therapy is effective in adult transplant recipients; however, the experience is limited in the pediatric setting, although phase I data have shown this agent was safe and well-tolerated in children [80-82]. Ceftolozane, a novel fifth-generation oxy-imino cephalosporin closely resembling ceftazidime, has been combined with the $\beta$-lactamase inhibitor tazobactam, with broad activity against chromosomal ampC $\beta$-lactamases in addition to potent antipseudomonal activity [83-85]. While only case reports describe its use in the pediatric setting, the potent activity towards pseudomonal isolates is likely to be of significant value in the LTx setting [86]. Imipenem/cilastatin/relebactam and meropenem/vaborbactam are novel carbapenem/ $\beta$-lactamase inhibitor combinations with a growing body of evidence to demonstrate potent activity towards carbapenem-resistant but non-metallo- $\beta$-lactamase (MBL) producing Enterobacteriaceae and Pseudomonas spp. [87-90]. While phase III data are lacking, imipenem/cilastatin/relebactam is likely to be an important antipseudomonal antibiotic with significant activity towards pseudomonal isolates with reduced oprD expression and ampC overexpression, two of the more prevalent mechanisms of high-level carbapenem resistance, in addition to high penetration into pulmonary tissues [87, 91-93]. Finally, the combination of ceftazidime/avibactam with aztreonam has demonstrated synergy in vitro towards MBL-producing Enterobacteriaceae, including those expressing $b l a_{\mathrm{IMP}}$ and $b l a_{\mathrm{NMD}}$ [94]. In a recent description of an outbreak in ten patients, four of whom were adult solid organ transplant (SOT) recipients, with extensively drugresistant New Delhi MBL (NDM)-1-producing K. pneumoniae infection, clinical success rates of $60 \%$ were observed without adverse effects. Although data to support the use of these newer agents in the pediatric setting are limited, adult data provides reason to hope these agents will prove to be safe and efficacious in the pediatric population, as they are proving to be in adults.

\section{Viral Pathogens}

\subsection{Hepatitis C Virus}

Lung donation from hepatitis $\mathrm{C}$ virus (HCV)-positive donors has historically been associated with high rates of viral transmission and subsequent inferior outcomes when compared with donation from HCV-negative donors [95-97]. Until recently, however, only hepatitis $\mathrm{C}$ serological testing was readily available to screen donors, leaving clinicians unable to differentiate those who were viremic (with high risk of transmission) from those who were non-viremic (or aviremic) (with negligible risk of transmission). With only serological testing available, this collective group of $\mathrm{HCV}$-positive donors were generally declined by transplant services. However, in recent times, attitudes to HCV-positive donors have begun to change, including those who are viremic and aviremic [97]. This reflects an increasing demand for organs, the changing epidemiology of HCV in the adult donor pool, ready access to nucleic acid tests (NATs) to determine viremic or aviremic status, and ready access to safe and effective direct-acting antivirals (DAAs). The increasing prevalence of $\mathrm{HCV}$ in the donor population, particularly in the USA, where up to $30 \%$ of the donor pool is $\mathrm{HCV}$ positive, has forced centers to consider HCV-positive expanded-criteria donors [97-100]. Pediatric recipients are not immune to this changing epidemiology, as the adolescent and adult population are accounting for an increasing percentage of the pediatric donor population [101-103].

The prevalence of $\mathrm{HCV}$ in the pediatric population is far below that in their adult counterparts and estimated to be between 0.05 and $0.36 \%$ in the USA and Europe [104]. However, there are concerns that this is likely an underestimation given the low prevalence of testing in this population [105]. The major route of transmission in children is vertical, from mother to child, and $60 \%$ of these cases will go on to develop chronic HCV, usually by age 2 [106]. Children are rarely symptomatic, so potential pediatric donors also require HCV screening prior to donation like their adult counterparts [107]. The same testing sequence used for screening adults, consisting of a $\mathrm{HCV}$ antibody assay followed by NAT testing if serology is positive, is recommended for the 
investigation of pediatric donors aged $>18$ months. Children aged $<18$ months should be screened with NAT only, as they are likely to have detectable maternal immunoglobulin [106].

The absolute number of pediatric LTx is increasing over time; as outcomes improve, more children are put on the waitlist. Waitlist mortality is greater in pediatric patients than in adults, so identifying suitable donors is often time critical [101, 103]. Donors aged $\geq 17$ years are increasingly represented among the donors for pediatric LTx, and, while the epidemiology of HCV in the pediatric pool is relatively static, the same cannot be said for the adult donor pool [97]. Therefore, pediatric transplant physicians are increasingly likely to be presented with either seropositive/NAT-negative or NAT-positive potential donor candidates for consideration. To meet the increasing organ demands, adult transplant centers are beginning to utilize both viremic and aviremic donors. The safety and efficacy of the interferon-sparing DAAs have allowed the treatment of $\mathrm{HCV}$ in transplant recipients without the predictably increased risk of rejection that complicated interferon-containing regimens. DAAs have successfully treated HCV in recipients of LTx and nonlung transplants $[108,109]$.

Unfortunately, evidence for the use of DAAs in the pediatric population lags behind that in their adult counterparts [110]. Until recently, evidence for the use of interferon-free regimens in pediatric patients was limited, but the body of evidence that these therapies are safe and highly effective in children is growing [111, 112]. Further work will need to be undertaken to establish whether these therapies are safe for use in pediatric LTx recipients.

Pediatric transplant centers are also likely to be offered seropositive/aviremic HCV donors for consideration. The authors encourage strong consideration be given to accepting these organs in the absence of other contraindications. There is no evidence that these donors have transmitted virus to adult recipients [97]. Interestingly, the authors and others have observed a phenomenon of persistent HCV seropositivity in the absence of detectable viremia in a subset of adult recipients of $\mathrm{HCV}$-seropositive/aviremic donor grafts [113-115]. The mechanisms for this seropositivity are unclear but do not appear to represent transmission of virus. They may represent a form of passenger lymphocyte syndrome, with memory B cells transplanted among allograft-associated lymphoid tissue. As published experience with these donor/recipient pairs is absent, we strongly suggest protocolized follow-up that includes both HCV serology and NAT testing within the first 7 days of transplant and regularly thereafter.

There is currently no evidence to support donation from the lungs of $\mathrm{HCV}$ viremic donors into pediatric recipients. While we await more robust evidence to support the efficacy and safety of DAA use in children, these donors should continue to be declined. However, the authors suggest that strong consideration be given to accepting donor lungs from seropositive/aviremic donors as they do not appear to represent a risk for viral transmission.

\subsection{Human Immunodeficiency Virus}

Outcomes for HIV-positive recipients who receive organs from HIV-positive or -negative donors appear favorable $[116,117]$. Evidence from inadvertent transplant of HIVpositive donors to HIV-negative recipients has shown good patient and graft survival [118]. Modern antiretroviral therapies can be safely administered post-LTx without major problematic drug-drug interactions. The risk of donorderived HIV from pediatric donors to pediatric recipients is extremely low, but the risk is greater from adult donors, which are increasingly represented as pediatric donors [119]. With growing interest in expanding the donor pool to address expanding waitlists, the need to consider otherwise viable organs from HIV-positive donors may become necessary [120].

\subsection{Cytomegalovirus}

Cytomegalovirus (CMV) continues to contribute to significant morbidity and mortality following LTx, and this is no different in the pediatric population. A member of the herpesvirus family, CMV demonstrates latency and, in the immunosuppressed CMV-seropositive LTx patient, an everpresent risk of reactivation [121]. Given that CMV seropositivity increases with age, the proportion of CMV-naïve LTx recipients is higher in the pediatric population than in adults. Depending on their size, pediatric LTx recipients may receive donor organs from both the pediatric and the adult organ donor pool, with the latter being much more commonly CMV seropositive. These epidemiological factors peculiar to the pediatric population mean that the incidence of CMV mismatches, whereby a CMV-naïve recipient (R-) is transplanted with lungs from a CMV-seropositive donor $(\mathrm{D}+)$, is higher in pediatric patients. Importantly, the subsequent risk of CMV infection and disease is higher in the CMV R-D + mismatched LTx recipient. Primary CMV infection in the R-D- child is also higher as a result of exposure in the community, especially around school attendance [122].

In the adult LTx population, CMV reactivation can be associated with direct end-organ disease and also indirect disease, including an association with secondary microbial infections and chronic lung allograft dysfunction (CLAD) [123, 124]. However, while CMV disease is associated with an increased 1-year mortality in pediatric LTx recipients, an association with opportunistic infections or CLAD has not been demonstrated [122]. 
Before the introduction of antiviral prophylaxis, viremia was seen in over $60 \%$ of LTx recipients, with almost half of these developing end-organ CMV disease [125]. With routine antiviral prophylaxis, CMV viremia and CMV pneumonitis is still seen in approximately $30 \%$ and $20 \%$ of pediatric LTx recipients, respectively [126]. Most centers advocate routine antiviral prophylaxis for all those at risk $(\mathrm{R}+\mathrm{D}+, \mathrm{R}+\mathrm{D}-$, or $\mathrm{R}-/ \mathrm{D}+)$, with a recent consensus statement advocating at least 3-6 months of antiviral prophylaxis using a combination of early intravenous ganciclovir followed by oral valganciclovir [127]. Prolonged 12-week courses of intravenous ganciclovir have been shown to be safe and efficacious in pediatric LTx recipients [128]. There are limited studies on the efficacy and safety of prolonged valganciclovir use in the pediatric transplant population for prophylaxis. Valganciclovir dosing algorithms that adjust for body surface area and renal function need to be used to ensure safe and effective dosing. In a retrospective review of pediatric LTx recipients from 14 sites, hyperimmune CMV immunoglobulin preparations decreased the risk of CMV infection, but not disease, after pediatric LTx [129].

Following cessation of antiviral prophylaxis, late CMV reactivation is common and associated with serious longterm consequences. Therefore, monitoring for viremia should continue for at least 3-6 months beyond the prophylaxis period. Weekly monitoring is recommended, but this can be logistically challenging to achieve. Data are starting to emerge on assays that determine the presence of host immunity to $\mathrm{CMV}$, and these are likely in the future to be incorporated into decisions regarding duration of antiviral prophylaxis in the individual patient [130, 131]. Recommendations on treatment of actual CMV disease in pediatric LTx recipients are largely extrapolated from data in the adult population and include the initial use of intravenous ganciclovir ( $5 \mathrm{mg} / \mathrm{kg}$ every $12 \mathrm{~h}$ ), adjusted to renal function. In severe disease, hyperimmune CMV immunoglobulin can be added. Where clinical or proven CMV resistance is apparent, foscarnet may be an appropriate substitute for ganciclovir. Secondary antiviral prophylaxis should be considered in children with recurrent CMV viremia.

\section{Immunization and Pediatric Lung Transplant (LTx)}

Pediatric LTx recipients are at increased risk of morbidity and mortality as a consequence of vaccine-preventable disease. Given that vaccines are less efficacious in the setting of immunosuppression, and that live attenuated vaccines (LAV) should be avoided, it is essential to ensure all children who may be considered for LTx are fully immunized.

The LTx assessment should be regarded as an opportunity to take a vaccine history and assess for humoral immunity to common vaccine-preventable disease. Many centers screen for immunity to hepatitis B, measles, mumps, rubella, and varicella to assist in tailoring individual immunization recommendations. Despite many countries having national childhood immunization programs, children with chronic illness may not be fully vaccinated [132]. It is important to note that those who have missed primary vaccination may need a more extensive catch-up schedule. As protective antibody titers can decrease over time [133, 134], levels should be periodically assessed following LTx and revaccination undertaken if required. It is recommended that family members, household contacts, and healthcare workers are assessed and vaccinated to provide additional protection to the transplant recipient.

\subsection{The Live Attenuated Vaccines}

Following LTx, LAVs should be avoided because of the risk of developing vaccine strain-disseminated disease. Special care should be taken to ensure LAVs are administered pre-LTx if required. While studies have examined the use of LAV following other SOT in children [133, 135-137], these trials were in carefully selected patients with reduced immunosuppression. These trials were predominantly undertaken in liver and kidney recipients, and such protocols are unlikely to ever be suitable for LTx recipients.

\subsubsection{Varicella Zoster Virus}

There is significant risk of disseminated disease and significant complications if primary VZV is contracted following LTx [138]. Immunization prior to LTx is recommended. In children aged $>9$ months, two doses 4 weeks apart are required, and humoral immunity should be assessed to ensure seroconversion. As the VZV vaccine is a $\mathrm{LAV}$, transplant should be delayed until 4 weeks after vaccination [139].

Following LTx, VZV vaccination should be avoided in those without evidence of detectable immunity. Exposure in this group should be treated with varicella immunoglobulin if available, and the antiviral acyclovir should be considered [138].

\subsubsection{Measles, Mumps, Rubella Viruses}

Measles has been previously regarded as an epidemic affecting predominantly children uncommonly seen in the developed world. However, with declining herd immunity as a result of vaccine avoidance, measles is becoming increasingly common [140]. Measles can cause significant morbidity and mortality in both immunocompetent and immunosuppressed individuals. As there is no antiviral treatment, immunization is the only defense available. 
The measles, mumps, rubella (MMR) vaccine is an LAV and can be used in children aged $\geq 6$ months. Two doses administered 4 weeks apart are required. MMR is a safe vaccine with high rates of seroconversion. Antibody titers should be checked following administration, and, as it is a LAV, transplant should be delayed until 4 weeks after vaccination [139].

\subsubsection{Rotavirus}

The rotavirus vaccine is a live oral vaccine usually given to infants on a 2- to 3-dose schedule from approximately 6 weeks of age [141]. It is not suitable after LTx due to the risk of significant infection. However, unlike other LAVs, it should be avoided in those awaiting LTx because of prolonged viral shedding. In immunocompetent children, viral shedding is seen for at least 28 days after first vaccination and can continue for up to 8 months [142].

\subsection{Inactivated Vaccines}

Inactivated vaccines are generally safe after LTx but should be delayed until the patient is on stable low-level immunosuppression [139]. This is generally approximately beyond 6 months post-LTx.

\subsubsection{Influenza Virus}

Seasonal influenza can cause significant morbidity and mortality following LTx [143]. Despite effectiveness varying from year to year, annual influenza vaccination remains one of the most effective ways to prevent disease. This inactivated vaccine is made up of A and B strains of influenza as recommended by the World Health Organization [144]. Seroconversion rates are reduced after SOT and are lowest in LTx recipients and those receiving mycophenolate mofetil $[145,146]$. Given lower rates of seroconversion, some transplant centers recommend two doses at least 4 weeks apart [147].

\subsubsection{Streptococcus Pneumoniae}

Streptococcus pneumoniae can cause catastrophic invasive disease in immunosuppressed children [148]. The inclusion of pneumococcal vaccination in national vaccination programs has significantly reduced the incidence of invasive disease in immunocompetent children [149] and, as such, the vaccination of all pediatric LTx candidates and recipients is essential.

Two vaccines are available: the 23 -valent polysaccharide vaccine (23PPV) and the 13-valent conjugate vaccine (13PCV). The 13PCV is used for primary vaccination as it has better immunogenicity than the 23PPV. However, a booster of $23 \mathrm{PPV}$ at least 8 weeks after $13 \mathrm{PCV}$ is recommended to provide protection against a broader range of serotypes [147].

\subsubsection{Hepatitis B Virus}

Hepatitis B virus (HBV) vaccination is now on most childhood immunization schedules. It is recommended for LTx candidates to provide both general protection against HBV and to decrease the risk of transmission if a HBV-positive donor is used [150]. If time is limited pre-LTx, an accelerated schedule can be used. HBV vaccination is safe following LTx, and any individual without detectable immunity should be offered vaccination. Seroconversion following transplantation has been reported at between 40 and $70 \%$ [151].

\subsubsection{Human Papilloma Virus}

The human papilloma virus (HPV) vaccine is the most recent vaccine to become available. The quadrivalent vaccine, which offers protection against HPV16 and HPV18, the major strains implicated in cervical cancer, and HPV 6 and 11, the strains responsible for $90 \%$ of genital warts, is most commonly used. A nine-valent vaccine has been approved for use in the USA but is not available in all jurisdictions. HPV disease in the form of warts causes significant morbidity after SOT [152]. As such, all transplant recipients between the ages of 11 and 26 years should be offered vaccination.

\section{Novel Approaches to LTx Infectious Disease}

\subsection{Nitric Oxide}

Inhaled nitric oxide (NO) is emerging as an antibiotic-sparing antimicrobial agent that may have a role as adjunctive therapy for treatment of MA and a range of other chronic infective pulmonary infections, including bacteria and fungi [153-155]. NO is a hydrophobic gas with broad reactivity, is rapidly diffusible, and has been demonstrated as safe when administered via multiple doses of 160 parts per million [153, 154, 156, 157]. Administration is preferably intermittent to avoid accumulation of toxic $\mathrm{NO}_{2}$, methemoglobin, and unacceptable hypoxemia [153, 158]. While various experimental platforms have been evaluated to deliver NO, including gaseous from a tank and generation from nanoparticles, no standardized or commercially available platforms are currently available for routine use [159].

Inhaled NO has demonstrated activity against bacterial and mycobacterial biofilms [154]. This may be of particular 
value when treating MA infections that have biofilm or biofilm-like aggregation as a recognized virulence factor [160]. Deppisch et al. [153] demonstrated in a phase I trial that eight patients with CF previously treated for chronic lung infection with prolonged antimycobacterials experienced a further reduction in colony-forming units of all bacteria and fungi, with an improvement in forced expiratory volume in $1 \mathrm{~s}\left(\mathrm{FEV}_{1}\right)$ when treated with inhaled $\mathrm{NO}$ alone [153]. Yaacoby-Bianu et al. [155] treated two patients with CF (aged 13 and 19 years) with intractable MA infection despite multidrug therapy and observed a reduction in the quantitative PCR load of MA; one patient experienced improved lung function. Further work is required before this therapy can be widely recommended, but it potentially provides a safe, adjunctive therapy against a range of infecting organisms in the peri-LTx setting.

\subsection{Microbiome Insights}

The microbiome is the term used to collectively describe the community of microorganisms that inhabit the body surfaces exposed to the outside world [161, 162]. Attempts to more clearly define the relationship between the microbiome, health, and health-related outcomes have seen an explosive outpouring of scientific literature. Investigation of the microbiomes in the lower respiratory tract of pediatric patients with $\mathrm{CF}$ has revealed that the microbiome changes over time. Infants have a relatively sterile lower airway and develop more complex bacterial communities in early childhood, dominated with species of organisms usually found in the mouth $[163,164]$. As these children age, the microbiome shifts to a pathogen-dominated microbiome with a progressive decrease in microbiome complexity that parallels a decline in lung function [163-165]. These longitudinal studies show significant negative correlations between patient age and microbiome community richness and diversity, and between age and pulmonary function $[163,166]$.

Adult and pediatric patients with CF also have a disruption of the gut microbiome when compared with healthy controls, with a trend to lower species richness and temporal stability suggesting fecal dysbiosis $[167,168]$. Furthermore, recurrent courses of antibiotics to treat pulmonary exacerbations have a dramatic effect on the commensal microbiota of these patients [169].

Much less is known about the microbiome of the transplanted lung. Infectious complications are the single greatest cause of morbidity and mortality in the first year post-LTx, highlighting the importance of the organisms that make up the microbiome post-LTx. There is also a strong observed link between infection and the risk of rejection, with further work beginning to delineate the role of the microbiome and immunological outcomes [170]. Charlson et al. [171] demonstrated that the microbiome in an LTx recipient's BAL differs in structure and composition from that of healthy controls. Willner et al. [172] demonstrated that recolonization of allograft by pre-LTx microbiome seems to have a protective effect against CLAD [172]. Work to establish the precise dynamics of the lung microbiome over time in LTx recipients and the relationship with immunomodulation and outcome is needed before any meaningful conclusions can be drawn. The microbiome of both the airway and other mucosal surfaces, particularly the gut, is likely to be a significant target for antibiotic-sparing immunomodulatory therapy in the future.

\section{Conclusion}

Numerous infectious issues challenge pediatric LTx recipients and their clinicians. Expanding interest in ways to broaden the donor pool has led to consideration of donation from blood-borne virus-positive recipients, particularly those with $\mathrm{HCV}$ and those considered at risk of blood-borne viruses at the time of donation. Recent positive experiences in adult LTx recipients will see these approaches eventually attempted in pediatric LTx. A better understanding of the peri-LTx management of mycoplasma, ureoplasma, and MA LTx infections is translating to novel strategies to tackle previously difficult clinical situations. CMV strategies are also evolving, with the promise of further gains as host immune monitoring is explored. However, the increasing emergence of resistant Gram-negative bacteria reminds us to continue to respect the complexity and effects of all our agents on our transplanted patient's microbiomes.

It is apparent that much has been learnt in recent years about infections in pediatric LTx patients, but many issues remain to be explored and translated. Watch this space.

\section{Compliance with Ethical Standards}

Conficts of interest O. C. Smibert, M. A. Paraskeva, G. Westall and G. Snell report on conflicts of interest.

Funding No sources of funding were used to support the writing of this manuscript.

\section{References}

1. Kirkby S, Hayes D. Pediatric lung transplantation: indications and outcomes. J Thorac Dis. 2014;6(8):1024-31. https://doi. org/10.3978/j.issn.2072-1439.2014.04.27.

2. Lund LH, Khush KK, Cherikh WS, et al. The registry of the international society for heart and lung transplantation: thirtyfourth adult heart transplantation report-2017; focus theme: allograft ischemic time. J Heart Lung Transpl. 2017;36(10):1037-46. https://doi.org/10.1016/j.healun.2017.07.019. 
3. Mufson MA. Mycoplasma hominis: a review of its role as a respiratory tract pathogen of humans. Sex Trans Dis. 1983;10(4 Suppl):335-40.

4. Waites KB, Katz B, Schelonka RL. Mycoplasmas and ureaplasmas as neonatal pathogens. Clin Microbiol Rev. 2005;18(4):757-89. https://doi.org/10.1128/ CMR.18.4.757-789.2005.

5. Fernandez R, Ratliff A, Crabb D, et al. Ureaplasma transmitted from donor lungs is pathogenic after lung transplantation. Ann Thorac Surg. 2017;103(2):670-1. https://doi.org/10.1016/j.athor acsur.2016.09.026.

6. Buckingham SC, Crouse DT, Knapp KM, et al. Pneumonitis associated with Ureaplasma urealyticum in children with cancer. Clin Infect Dis. 2003;36(2):225-8. https://doi.org/10.1086/34566 7.

7. Lilla L, Edit S, Eva K. Detection of Mycoplasma species in urinary tract infections in children. Bacteriol Virusol Parazitol Epidemiol (Bucharest, Romania: 1990). 2004;49(1-2):33-6.

8. Pinna GS, Skevaki CL, Kafetzis DA. The significance of ureaplasma urealyticum as a pathogenic agent in the paediatric population. Curr Opin Infect Dis. 2006;19(3):283-9. https://doi. org/10.1097/01.qco.0000224824.73223.e7.

9. Cho H, Park KG, Han SB, et al. First Case of skin and soft tissue infection caused by mycoplasma hominis in a pediatric immunocompromised patient. Ann Lab Med. 2017;37(4):346-8. https ://doi.org/10.3343/alm.2017.37.4.346.

10. Dixit A, Alexandrescu S, Boyer D, et al. Mycoplasma hominis empyema in an 18-year-old stem cell and lung transplant recipient: case report and review of the literature. J Pediatr Infect Dis Soc. 2017;6(4):e173-6. https://doi.org/10.1093/jpids/pix049.

11. Sato M, Kubota N, Katsuyama Y, et al. Case report of a 6-yearold girl with Mycoplasma hominis ventriculoperitoneal shunt infection. J Neurosurg Pediatr. 2017;19(5):620-4. https://doi. org/10.3171/2017.1.peds 16520 .

12. Whitson WJ, Ball PA, Lollis SS, et al. Postoperative mycoplasma hominis infections after neurosurgical intervention. J Neurosurg Pediatr. 2014;14(2):212-8. https://doi.org/10.3171/2014.4.peds1 3547.

13. Sampath R, Patel R, Cunningham SA, et al. Cardiothoracic transplant recipient mycoplasma hominis: an uncommon infection with probable donor transmission. EBioMedicine. 2017;19:8490. https://doi.org/10.1016/j.ebiom.2017.04.026.

14. Smibert OC, Wilson HL, Sohail A, et al. Donor-derived mycoplasma hominis and an apparent cluster of m. hominis cases in solid organ transplant recipients. Clin Infect Dis Am. 2017;65(9):1504-8. https://doi.org/10.1093/cid/cix601.

15. Waites Ken B T-RD. Mycoplasma and Ureaplasma. In: Jorgensen $\mathrm{JH}$, Pfaller MA, Carroll KC, et al., editors. Manual of clinical microbiology, 11th edn. ed. p. 2 volumes (xxvii, 2,571, xxix-clix pages).

16. Waites KB, Xiao L, Paralanov V, et al. Molecular methods for the detection of Mycoplasma and ureaplasma infections in humans: a paper from the 2011 William Beaumont Hospital Symposium on molecular pathology. JMD. 2012;14(5):437-50. https://doi. org/10.1016/j.jmoldx.2012.06.001.

17. Cunningham SA, Mandrekar JN, Rosenblatt JE, et al. Rapid PCR detection of mycoplasma hominis, ureaplasma urealyticum, and ureaplasma parvum. Int J Bacteriol. 2013;2013:168742. https:// doi.org/10.1155/2013/168742.

18. Mardassi BB, Aissani N, Moalla I, et al. Evidence for the predominance of a single tet(M) gene sequence type in tetracyclineresistant Ureaplasma parvum and Mycoplasma hominis isolates from Tunisian patients. J Med Microbiol. 2012;61(Pt 9):125461. https://doi.org/10.1099/jmm.0.044016-0.

19. Xiao L, Crabb DM, Duffy LB, et al. Mutations in ribosomal proteins and ribosomal RNA confer macrolide resistance in human
Ureaplasma spp. Int J Antimicrob Agents. 2011;37(4):377-9. https://doi.org/10.1016/j.ijantimicag.2010.12.012.

20. Bharat A, Cunningham SA, Scott Budinger GR, et al. Disseminated ureaplasma infection as a cause of fatal hyperammonemia in humans. Sci Transl Med. 2015;7(284):284re3. https://doi. org/10.1126/scitranslmed.aaa8419.

21. Gass R, Fisher J, Badesch D, et al. Donor-to-host transmission of Mycoplasma hominis in lung allograft recipients. Clin Infect Dis. 1996;22(3):567-8.

22. Lyon GM, Alspaugh JA, Meredith FT, et al. Mycoplasma hominis pneumonia complicating bilateral lung transplantation: case report and review of the literature. Chest. 1997;112(5):1428-32.

23. Hopkins P. A cluster of mycoplasma hominis infection in heartlung transplantation. J Heart Lung Transpl. 2001;20(2):223-4.

24. Moffatt-Bruce SD, Pesavento T, Von Viger J, et al. Successful management of immunosuppression in a patient with severe hyperammonemia after lung transplantation. J Heart Lung Transpl. 2008;27(7):801-3. https://doi.org/10.1016/j.healu n.2008.03.019.

25. Wang X, Greenwood-Quaintance KE, Karau MJ, et al. Ureaplasma parvum causes hyperammonemia in a pharmacologically immunocompromised murine model. Eur J Clin Microbiol Infect Dis. 2017;36(3):517-22. https://doi.org/10.1007/s1009 6-016-2827-1.

26. Anwar S, Gupta D, Ashraf MA, et al. Symptomatic hyperammonemia after lung transplantation: lessons learnt. Hemodial Int Int Symp Home Hemodial. 2014;18(1):185-91. https://doi. org/10.1111/hdi.12088.

27. Lichtenstein GR, Kaiser LR, Tuchman M, et al. Fatal hyperammonemia following orthotopic lung transplantation. Gastroenterology. 1997;112(1):236-40.

28. Chen C, Bain KB, Iuppa JA, et al. Hyperammonemia syndrome after lung transplantation: a single center experience. Transplantation. 2016;100(3):678-84. https://doi.org/10.1097/tp.00000 00000000868

29. Aitken ML, Limaye A, Pottinger P, et al. Respiratory outbreak of Mycobacterium abscessus subspecies massiliense in a lung transplant and cystic fibrosis center. Am J Respir Crit Care Med. 2012;185(2):231-2. https://doi.org/10.1164/ajrccm.185.2.231.

30. Osmani M, Sotello D, Alvarez S, et al. Mycobacterium abscessus infections in lung transplant recipients: 15-year experience from a single institution. Transpl Infect Dis. 2018;20(2):e12835. https ://doi.org/10.1111/tid.12835.

31. Smibert O, Snell GI, Bills H, et al. Mycobacterium abscessus complex - a particular challenge in the setting of lung transplantation. Expert Rev Anti-Infect Ther. 2016;14(3):325-33. https:// doi.org/10.1586/14787210.2016.1138856.

32. Bills H, Snell G, Levvey B, et al. Mycobacterium abscessus and lung transplantation: an international survey. J Heart Lung Transpl. 2015;34(4):S304. https://doi.org/10.1016/j.healu n.2015.01.856.

33. Knoll BM. Update on nontuberculous mycobacterial infections in solid organ and hematopoietic stem cell transplant recipients. Curr Infect Dis Rep. 2014;16(9):421. https://doi.org/10.1007/ s11908-014-0421-1.

34. Lobo LJ, Chang LC, Esther CR Jr, et al. Lung transplant outcomes in cystic fibrosis patients with pre-operative $\mathrm{Myco}$ bacterium abscessus respiratory infections. Clin Transpl. 2013;27(4):523-9. https://doi.org/10.1111/ctr.12140.

35. Qvist T, Pressler T, Thomsen VO, et al. Nontuberculous mycobacterial disease is not a contraindication to lung transplantation in patients with cystic fibrosis: a retrospective analysis in a Danish patient population. Transpl Proc. 2013;45(1):342-5. https:// doi.org/10.1016/j.transproceed.2012.02.035.

36. Robinson PD, Harris KA, Aurora P, et al. Paediatric lung transplant outcomes vary with Mycobacterium abscessus complex 
species. The European respiratory journal. 2013;41(5):1230-2. https://doi.org/10.1183/09031936.00143512.

37. Bar-On O, Mussaffi H, Mei-Zahav M, et al. Increasing nontuberculous mycobacteria infection in cystic fibrosis. J Cyst Fibrosis. 2015;14(1):53-62. https://doi.org/10.1016/j.jcf.2014.05.008.

38. Bryant JM, Grogono DM, Rodriguez-Rincon D, et al. Emergence and spread of a human-transmissible multidrug-resistant nontuberculous mycobacterium. Science (New York, NY). 2016;354(6313):751-7. https://doi.org/10.1126/science.aaf8156.

39. Sabin AP, Ferrieri P, Kline S. Mycobacterium abscessus complex infections in children: a review. Curr Infect Dis Rep. 2017;19(11):46. https://doi.org/10.1007/s11908-017-0597-2.

40. Mougari F, Amarsy R, Veziris N, et al. Standardized interpretation of antibiotic susceptibility testing and resistance genotyping for Mycobacterium abscessus with regard to subspecies and erm41 sequevar. J Antimicrob Chemother. 2016;71(8):2208-12. https://doi.org/10.1093/jac/dkw130.

41. Mougari F, Bouziane F, Crockett F, et al. Selection of resistance to clarithromycin in Mycobacterium abscessus subspecies. Antimicrob Agents Chemother. 2017. 61(1):e00943-16. https:// doi.org/10.1128/aac.00943-16.

42. Diel R, Ringshausen F, Richter E, et al. Microbiological and clinical outcomes of treating non-mycobacterium avium complex nontuberculous mycobacterial pulmonary disease: a systematic review and meta-analysis. Chest. 2017;152(1):120-42. https:// doi.org/10.1016/j.chest.2017.04.166.

43. Harada T, Akiyama Y, Kurashima A, et al. Clinical and microbiological differences between Mycobacterium abscessus and Mycobacterium massiliense lung diseases. J Clin Microbiol. 2012;50(11):3556-61. https://doi.org/10.1128/jcm.01175-12.

44. Koh WJ, Jeong BH, Kim SY, et al. Mycobacterial characteristics and treatment outcomes in Mycobacterium abscessus lung disease. Clin Infect Dis. 2047;64(3):309-16. https://doi. org/10.1093/cid/ciw724.

45. Park J, Cho J, Lee CH, et al. Progression and treatment outcomes of lung disease caused by Mycobacterium abscessus and Mycobacterium massiliense. Clin Infect Dis. 2017;64(3):301-8. https ://doi.org/10.1093/cid/ciw723.

46. Pasipanodya JG, Ogbonna D, Ferro BE, et al. Systematic review and meta-analyses of the effect of chemotherapy on pulmonary Mycobacterium abscessus outcomes and disease recurrence. Antimicrob Agents Chemother. 2017;61(11). https://doi. org/10.1128/aac.01206-17.

47. Roux AL, Catherinot E, Soismier N, et al. Comparing Mycobacterium massiliense and Mycobacterium abscessus lung infections in cystic fibrosis patients. J Cyst Fibrosis. 2015;14(1):63-9. https ://doi.org/10.1016/j.jcf.2014.07.004.

48. Baker AW, Lewis SS, Alexander BD, et al. Two-phase hospitalassociated outbreak of Mycobacterium abscessus: investigation and mitigation. Clin Infect Dis. 2017;64(7):902-11. https://doi. org/10.1093/cid/ciw877.

49. Caskey S, Moore JE, Rendall JC. In vitro activity of seven hospital biocides against Mycobacterium abscessus: implications for patients with cystic fibrosis. Int J Mycobacteriol. 2018;7(1):4547. https://doi.org/10.4103/ijmy.ijmy_197_17.

50. Bryant JM, Grogono DM, Greaves D, et al. Whole-genome sequencing to identify transmission of Mycobacterium abscessus between patients with cystic fibrosis: a retrospective cohort study. Lancet (London, England). 2013;381(9877):1551-60. https://doi. org/10.1016/s0140-6736(13)60632-7.

51. Mougari F, Guglielmetti L, Raskine L, et al. Infections caused by Mycobacterium abscessus: epidemiology, diagnostic tools and treatment. Expert Rev Anti Infect Ther. 2016;14(12):1139-54. https://doi.org/10.1080/14787210.2016.1238304.

52. Fletcher LA, Chen Y, Whitaker P, et al. Survival of Mycobacterium abscessus isolated from people with cystic fibrosis in artificially generated aerosols. Eur Respir J. 2016;48(6):1789-91. https://doi.org/10.1183/13993003.00849-2016.

53. Harris KA, Underwood A, Kenna DT, et al. Whole-genome sequencing and epidemiological analysis do not provide evidence for cross-transmission of Mycobacterium abscessus in a cohort of pediatric cystic fibrosis patients. Clin Infect Dis. 2015;60(7):1007-16. https://doi.org/10.1093/cid/ciu967.

54. Saiman L, Siegel JD, LiPuma JJ, et al. Infection prevention and control guideline for cystic fibrosis: 2013 update. Infect Control Hosp Epidemiol. 2014;35(Suppl 1):S1-67. https://doi. org/10.1086/676882.

55. Li B, Yang S, Chu H, et al. Relationship between antibiotic susceptibility and genotype in Mycobacterium abscessus clinical isolates. Front Microbiol. 2017;8:1739. https://doi.org/10.3389/ fmicb.2017.01739.

56. Hurst-Hess K, Rudra P, Ghosh P. Mycobacterium abscessus WhiB7 regulates a species-specific repertoire of genes to confer extreme antibiotic resistance. Antimicrob Agents Chemother. 2017. https://doi.org/10.1128/aac.01347-17.

57. Pryjma M, Burian J, Kuchinski K, et al. Antagonism between front-line antibiotics clarithromycin and amikacin in the treatment of Mycobacterium abscessus infections is mediated by the whiB7 gene. Antimicrob Agents Chemother. 2017. https://doi. org/10.1128/aac.01353-17.

58. Carneiro MDS, Nunes LS, David SMM, et al. Lack of association between rrl and erm(41) mutations and clarithromycin resistance in Mycobacterium abscessus complex. Mem Inst Oswaldo Cruz. 2017;112(11):775-8. https://doi.org/10.1590/0074-0276017008 0 .

59. Carvalho NFG, Pavan F, Sato DN, et al. Genetic correlates of clarithromycin susceptibility among isolates of the Mycobacterium abscessus group and the potential clinical applicability of a PCR-based analysis of erm(41). J Antimicrob Chemother. 2018;73(4):862-6. https://doi.org/10.1093/jac/dkx476.

60. Griffith DE, Aksamit T, Brown-Elliott BA, et al. An official ATS/IDSA statement: diagnosis, treatment, and prevention of nontuberculous mycobacterial diseases. Am J Respir Crit Care Med. 2007;175(4):367-416. https://doi.org/10.1164/rccm.20060 4-571ST.

61. Scott JP, Ji Y, Kannan M, et al. Inhaled granulocyte-macrophage colony-stimulating factor for Mycobacterium abscessus in cystic fibrosis. Eur Respir J. 2018. https://doi.org/10.1183/13993 003.02127-2017.

62. Soroka D, Dubee V, Soulier-Escrihuela O, et al. Characterization of broad-spectrum Mycobacterium abscessus class A betalactamase. J Antimicrob Chemother. 2014;69(3):691-6. https:// doi.org/10.1093/jac/dkt410.

63. Dubee V, Soroka D, Cortes M, et al. Impact of beta-lactamase inhibition on the activity of ceftaroline against Mycobacterium tuberculosis and Mycobacterium abscessus. Antimicrob Agents Chemother. 2015;59(5):2938-41. https://doi.org/10.1128/ aac.05080-14.

64. Kaushik A, Gupta C, Fisher S, et al. Combinations of avibactam and carbapenems exhibit enhanced potencies against drug-resistant Mycobacterium abscessus. Future Microbiol. 2017;12:47380. https://doi.org/10.2217/fmb-2016-0234.

65. Lefebvre AL, Le Moigne $\mathrm{V}$, Bernut $\mathrm{A}$, et al. Inhibition of the beta-Lactamase BlaMab by Avibactam Improves the In Vitro and In Vivo Efficacy of Imipenem against Mycobacterium abscessus. Antimicrob Agents Chemother. 2017. https://doi.org/10.1128/ aac.02440-16.

66. Zhang $\mathrm{Z}, \mathrm{Lu} \mathrm{J}$, Liu M, et al. In vitro activity of clarithromycin in combination with other antimicrobial agents against Mycobacterium abscessus and Mycobacterium massiliense. Int $\mathrm{J}$ Antimicrob Agents. 2017;49(3):383-6. https://doi.org/10.1016/j.ijant imicag.2016.12.003. 
67. Zhang Z, Lu J, Song Y, et al. In vitro activity between linezolid and other antimicrobial agents against Mycobacterium abscessus complex. Diagn Microbiol Infect Dis. 2018;90(1):31-4. https:// doi.org/10.1016/j.diagmicrobio.2017.09.013.

68. Aguado JM, Silva JT, Fernandez-Ruiz M, et al. Management of multidrug resistant Gram-negative bacilli infections in solid organ transplant recipients: SET/GESITRA-SEIMC/REIPI recommendations. Transpl Rev (Orlando, Fla). 2018;32(1):36-57. https://doi.org/10.1016/j.trre.2017.07.001.

69. Cervera C, Linares L, Bou G, et al. Multidrug-resistant bacterial infection in solid organ transplant recipients. Enferm Infecc Microbiol Clin. 2012;30(Suppl 2):40-8. https://doi.org/10.1016/ s0213-005x(12)70081-2.

70. Patel G, Perez F, Bonomo RA. Carbapenem-resistant Enterobacteriaceae and Acinetobacter baumannii: assessing their impact on organ transplantation. Curr Opin Org Transpl. 2010;15(6):67682. https://doi.org/10.1097/MOT.0b013e3283404373.

71. Rutter WC, Burgess DR, Burgess DS. Increasing incidence of multidrug resistance among cystic fibrosis respiratory bacterial isolates. Microb Drug Resist (Larchmont, NY). 2017;23(1):5155. https://doi.org/10.1089/mdr.2016.0048.

72. Hadjiliadis D, Steele MP, Chaparro C, et al. Survival of lung transplant patients with cystic fibrosis harboring panresistant bacteria other than Burkholderia cepacia, compared with patients harboring sensitive bacteria. J Heart Lung Transpl. 2007;26(8):834-8. https://doi.org/10.1016/j.healun.2007.05.018.

73. Heldman M, Melson B, Babu T, et al., editors. Treatment of multi-drug resistant gram negative infections after solid organ transplant. 2018 American Transplant Congress; 2018; Washington.

74. Rogers BA, Aminzadeh Z, Hayashi Y, et al. Country-to-country transfer of patients and the risk of multi-resistant bacterial infection. Clin Infect Dis. 2011;53(1):49-56. https://doi.org/10.1093/ cid/cir273.

75. Mularoni A, Bertani A, Vizzini G, et al. Outcome of transplantation using organs from donors infected or colonized with carbapenem-resistant Gram-negative bacteria. Am J Transpl. 2015;15(10):2674-82. https://doi.org/10.1111/ajt.13317.

76. Alatoom A, Elsayed H, Lawlor K, et al. Comparison of antimicrobial activity between ceftolozane-tazobactam and ceftazidime-avibactam against multidrug-resistant isolates of Escherichia coli, Klebsiella pneumoniae, and Pseudomonas aeruginosa. IJID. 2017;62:39-43. https://doi.org/10.1016/j.ijid.2017.06.007.

77. de Jonge BL, Karlowsky JA, Kazmierczak KM, et al. In vitro susceptibility to ceftazidime-avibactam of carbapenem-nonsusceptible enterobacteriaceae isolates collected during the inform global surveillance study (2012 to 2014). Antimicrob Agents Chemother. 2016;60(5):3163-9. https://doi.org/10.1128/aac.03042-15.

78. Haidar G, Clancy CJ, Chen L, et al. Identifying spectra of activity and therapeutic niches for ceftazidime-avibactam and imipenemrelebactam against carbapenem-resistant enterobacteriaceae. Antimicrob Agents Chemother. 2017. https://doi.org/10.1128/ aac.00642-17.

79. Sader HS, Mendes RE, Pfaller MA, et al. Antimicrobial activities of aztreonam-avibactam and comparator agents against contemporary (2016) Clinical enterobacteriaceae isolates. Antimicrob Agents Chemother. 2018. https://doi.org/10.1128/aac.01856-17.

80. Bradley JS, Armstrong J, Arrieta A, et al. Phase I study assessing the pharmacokinetic profile, safety, and tolerability of a single dose of ceftazidime-avibactam in hospitalized pediatric patients. Antimicrob Agents Chemother. 2016;60(10):6252-9. https://doi. org/10.1128/aac.00862-16.

81. Shields RK, Nguyen MH, Chen L, et al. Ceftazidime-avibactam is superior to other treatment regimens against carbapenemresistant klebsiella pneumoniae bacteremia. Antimicrob Agents Chemother. 2017. https://doi.org/10.1128/aac.00883-17.
82. Tumbarello M, Trecarichi EM, Corona A, et al. Efficacy of ceftazidime-avibactam salvage therapy in patients with infections caused by KPC-producing klebsiella pneumoniae. Clin Infect Dis. 2018. https://doi.org/10.1093/cid/ciy492.

83. Giacobbe DR, Bassetti M, De Rosa FG, et al. Ceftolozane/tazobactam: place in therapy. Expert Rev Anti Infect Ther. 2018;16(4):307-20. https://doi.org/10.1080/14787 210.2018.1447381.

84. Pfaller MA, Shortridge D, Sader HS, et al. Ceftolozane/tazobactam activity against drug-resistant Enterobacteriaceae and Pseudomonas aeruginosa causing healthcare-associated infections in the Asia-Pacific region (minus China, Australia and New Zealand): report from an Antimicrobial Surveillance Programme (2013-2015). Int J Antimicrob Agents. 2018;51(2):181-9. https ://doi.org/10.1016/j.ijantimicag.2017.09.016.

85. Shortridge D, Pfaller MA, Castanheira M, et al. Antimicrobial activity of ceftolozane-tazobactam tested against enterobacteriaceae and pseudomonas aeruginosa with various resistance patterns isolated in U.S. Hospitals (2013-2016) as part of the surveillance program: program to assess ceftolozane-tazobactam susceptibility. Microb Drug Resist (Larchmont, NY). 2018;24(5):563-577. https://doi.org/10.1089/mdr.2017.0266.

86. Aitken SL, Kontoyiannis DP, DePombo AM, et al. Use of ceftolozane/tazobactam in the treatment of multidrug-resistant pseudomonas aeruginosa bloodstream infection in a pediatric leukemia patient. Pediatr Infect Dis J. 2016;35(9):1040-2. https ://doi.org/10.1097/inf.0000000000001228.

87. Lapuebla A, Abdallah M, Olafisoye O, et al. Activity of meropenem combined with RPX7009, a novel beta-lactamase inhibitor, against Gram-negative clinical isolates in New York City. Antimicrob Agents Chemother. 2015;59(8):4856-60. https://doi. org/10.1128/aac.00843-15.

88. Livermore DM, Warner M, Mushtaq S. Activity of MK-7655 combined with imipenem against enterobacteriaceae and pseudomonas aeruginosa. J Antimicrob Chemother. 2013;68(10):2286-90. https://doi.org/10.1093/jac/dkt178.

89. Lob SH, Hoban DJ, Young K, et al. Activity of imipenem-relebactam against Gram-Negative bacilli from global ICU and non-ICU wards-SMART 2015-2016. J Glob Antimicrob Resist. 2018. https://doi.org/10.1016/j.jgar.2018.05.017.

90. Zhanel GG, Lawrence CK, Adam H, et al. Imipenem-relebactam and meropenem-vaborbactam: two novel carbapenem-beta-lactamase inhibitor combinations. Drugs. 2018;78(1):65-98. https ://doi.org/10.1007/s40265-017-0851-9.

91. Gomez-Simmonds A, Stump S, Giddins MJ, et al. Clonal background, resistance gene profile, and porin gene mutations modulate in vitro susceptibility to imipenem-relebactam in diverse enterobacteriaceae. Antimicrob Agents Chemother. 2018. https ://doi.org/10.1128/aac.00573-18.

92. Rostami S, Farajzadeh Sheikh A, Shoja S, et al. Investigating of four main carbapenem-resistance mechanisms in high-level carbapenem resistant Pseudomonas aeruginosa isolated from burn patients. JCMA. 2018;81(2):127-32. https://doi.org/10.1016/j. jcma.2017.08.016.

93. Rizk ML, Rhee EG, Jumes PA, et al. Intrapulmonary pharmacokinetics of relebactam, a novel beta-lactamase inhibitor, dosed in combination with imipenem-cilastatin in healthy subjects. Antimicrob Agents Chemother. 2018. https://doi.org/10.1128/ aac.01411-17.

94. Jayol A, Nordmann P, Poirel L, et al. Ceftazidime/avibactam alone or in combination with aztreonam against colistin-resistant and carbapenemase-producing Klebsiella pneumoniae. J Antimicrob Chemother. 2018;73(2):542-4. https://doi.org/10.1093/jac/ dkx393.

95. Englum BR, Ganapathi AM, Speicher PJ, et al. Impact of donor and recipient hepatitis $\mathrm{C}$ status in lung transplantation. J Heart 
Lung Transpl. 2016;35(2):228-35. https://doi.org/10.1016/j. healun.2015.10.012.

96. Kling CE, Perkins JD, Landis CS, et al. Utilization of organs from donors according to hepatitis $\mathrm{C}$ antibody and nucleic acid testing status: time for change. Am J Transpl. 2017. https://doi. org/10.1111/ajt.14386.

97. Levitsky J, Formica RN, Bloom RD, et al. The American Society of Transplantation Consensus Conference on the use of hepatitis $\mathrm{C}$ viremic donors in solid organ transplantation. Am J Transpl. 2017. https://doi.org/10.1111/ajt.14381.

98. Coilly A, Samuel D. Pros and Cons: usage of organs from donors infected with hepatitis $\mathrm{C}$ virus-revision in the directacting antiviral era. J Hepatol. 2016;64(1):226-31. https://doi. org/10.1016/j.jhep.2015.09.002.

99. Fishman JA, Forns X. HCV-positive donor organs in solid organ transplantation: "mind the gap!". Am J Transpl. 2017. https://doi. org/10.1111/ajt.14396.

100. Bowring MG, Kucirka LM, Massie AB, et al. Changes in utilization and discard of hepatitis c-infected donor livers in the recent era. Am J Transpl. 2017;17(2):519-27. https://doi.org/10.1111/ ajt.13976.

101. Goldfarb SB, Levvey BJ, Cherikh WS, et al. Registry of the international society for heart and lung transplantation: twentieth pediatric lung and heart-lung transplantation report: 2017 Focus Theme Allograft ischemic time. J Heart Lung Transpl. 36(10):1070-1079. https://doi.org/10.1016/j.healun.2017.07.017.

102. Hayes D Jr, Black SM, Tobias JD, et al. Influence of donor and recipient age in lung transplantation. J Heart Lung Transpl. 2015;34(1):43-9. https://doi.org/10.1016/j.healun.2014.08.017.

103. Hayes D Jr, McConnell PI, Galantowicz M, et al. Outcomes in pediatric lung transplant recipients receiving adult allografts. Ann Thorac Surg. 2015;99(4):1184-91. https://doi.org/10.1016/j. athoracsur.2014.12.008.

104. Petruzziello A, Marigliano S, Loquercio G, et al. Global epidemiology of hepatitis $C$ virus infection: an up-date of the distribution and circulation of hepatitis $\mathrm{C}$ virus genotypes. World $\mathrm{J}$ Gastroenterol. 2016;22(34):7824-40. https://doi.org/10.3748/wjg.v22. i34.7824.

105. Delgado-Borrego A, Smith L, Jonas MM, et al. Expected and actual case ascertainment and treatment rates for children infected with hepatitis C in Florida and the United States: epidemiologic evidence from statewide and nationwide surveys. J Pediatr. 2012;161(5):915-21. https://doi.org/10.1016/j.jpeds .2012.05.002

106. Mack CL, Gonzalez-Peralta RP, Gupta N, et al. NASPGHAN practice guidelines: diagnosis and management of hepatitis $\mathrm{C}$ infection in infants, children, and adolescents. J Pediatr Gastroenterol Nutr. 2012;54(6):838-55. https://doi.org/10.1097/ MPG.0b013e318258328d.

107. Squires JE, Balistreri WF. Hepatitis $C$ virus infection in children and adolescents. Hepatol Commun. 2017;1(2):87-98. https://doi. org/10.1002/hep4.1028.

108. Theodoropoulos N, Whitson BA, Martin SI, et al. Successful treatment of donor-derived hepatitis $\mathrm{C}$ infection in a lung transplant recipient. Transpl Inf Dis. 2017. https://doi.org/10.1111/ tid. 12659 .

109. Khan B, Singer LG, Lilly LB, et al. Successful lung transplantation from hepatitis $\mathrm{C}$ positive donor to seronegative recipient. Am J Transpl. 2017;17(4):1129-31. https://doi.org/10.1111/ ajt.14137.

110. Serranti D, Indolfi G, Resti M. New treatments for chronic hepatitis C: an overview for paediatricians. WJG. 2014;20(43):1596574. https://doi.org/10.3748/wjg.v20.i43.15965.

111. Rizza SA, Nehra V, Temesgen Z. Sofosbuvir/ledipasvir fixeddose combination for treatment of chronic hepatitis $\mathrm{C}$ virus infection in children. Drugs Today (Barcelona, Spain: 1998).
2017;53(8):447-51. https://doi.org/10.1358/dot.2017.53.8.26875 29.

112. Wirth S, Rosenthal P, Gonzalez-Peralta RP, et al. Sofosbuvir and ribavirin in adolescents 12-17 years old with hepatitis $\mathrm{C}$ virus genotype 2 or 3 infection. Hepatology (Baltimore, Md). 2017;66(4):1102-10. https://doi.org/10.1002/hep.29278.

113. Agarwal N, Davis RJ, Gracey DM, et al. Detection of Hepatitis $\mathrm{C}$ antibodies without viral transmission in Hepatitis $\mathrm{C}$ negative recipients receiving kidneys from Hepatitis $\mathrm{C}$ positive donors treated with Direct Acting Anti-Viral Therapy. Transplantation. 2017. https://doi.org/10.1097/tp.0000000000002034.

114. Tenderich G, Zittermann A, Prohaska W, et al. Frequent detection of hepatitis B core antibodies in heart transplant recipients without preceding hepatitis B infection. Transpl Proc. 2005;37(10):4522-4. https://doi.org/10.1016/j.transproce ed.2005.11.025.

115. Wachs ME, Amend WJ, Ascher NL, et al. The risk of transmission of hepatitis B from $\mathrm{HBsAg}(-), \mathrm{HBcAb}(+), \operatorname{HBIgM(}(-)$ organ donors. Transplantation. 1995;59(2):230-4.

116. Medical Advisory Secretariat. Kidney and liver organ transplantation in persons with human immunodeficiency virus: an evidence-based analysis. Ont Health Technol Assess Ser. 2010;10(4):1-56.

117. Muller E, Barday Z, Mendelson M, et al. HIV-positive-to-HIVpositive kidney transplantation-results at 3 to 5 years. N Engl J Med. 2015;372(7):613-20. https://doi.org/10.1056/NEJMoa1408 896.

118. Lin S, Tsai M, CY L, et al., editors. Outcomes of solid organ transplantation from an hiv positive donor to negative recipients. American Transplant Congress; 2016; Boston, Massachusetts.

119. Green M, Covington S, Taranto S, et al. Pediatrics and donorderived disease transmission: the US OPTN experience. Pediatr Transpl. 2018. https://doi.org/10.1111/petr.13115.

120. Irwin L, Kotton CN, Elias N, et al. Utilization of increased risk for transmission of infectious disease donor organs in solid organ transplantation: retrospective analysis of disease transmission and safety. Transpl Inf Dis. 2017. https://doi.org/10.1111/ tid.12791.

121. Fishman JA. Infection in solid-organ transplant recipients. N Engl J Med. 2007;357(25):2601-14. https://doi.org/10.1056/NEJMr a064928.

122. Danziger-Isakov LA, Worley S, Michaels MG, et al. The risk, prevention, and outcome of cytomegalovirus after pediatric lung transplantation. Transplantation. 2009;87(10):1541-8. https:// doi.org/10.1097/TP.0b013e3181a492e8.

123. Paraskeva M, Bailey M, Levvey BJ, et al. Cytomegalovirus replication within the lung allograft is associated with bronchiolitis obliterans syndrome. Am J Transpl. 2011;11(10):2190-6. https ://doi.org/10.1111/j.1600-6143.2011.03663.x.

124. Paya CV. Indirect effects of CMV in the solid organ transplant patient. Transpl Inf Dis. 1999;1(Suppl 1):8-12.

125. Duncan AJ, Dummer JS, Paradis IL, et al. Cytomegalovirus infection and survival in lung transplant recipients. J Heart Lung Transpl. 1991;10(5 Pt 1):638-44 (discussion 645-6).

126. Danziger-Isakov LA, DelaMorena M, Hayashi RJ, et al. Cytomegalovirus viremia associated with death or retransplantation in pediatric lung-transplant recipients. Transplantation. 2003;75(9):1538-43. https://doi.org/10.1097/01.tp.0000061607 07985.bd.

127. Kotton CN, Kumar D, Caliendo AM, et al. Updated international consensus guidelines on the management of cytomegalovirus in solid-organ transplantation. Transplantation. 2013;96(4):333-60. https://doi.org/10.1097/TP.0b013e31829df29d.

128. Spivey JF, Singleton D, Sweet S, et al. Safety and efficacy of prolonged cytomegalovirus prophylaxis with intravenous ganciclovir in pediatric and young adult lung transplant recipients. 
Pediatr Transpl. 2007;11(3):312-8. https://doi.org/10.111 1/j.1399-3046.2006.00626.x.

129. Ranganathan K, Worley S, Michaels MG, et al. Cytomegalovirus immunoglobulin decreases the risk of cytomegalovirus infection but not disease after pediatric lung transplantation. J Heart Lung Transpl. 2009;28(10):1050-6. https://doi.org/10.1016/j. healun.2009.04.032.

130. Patel M, Stefanidou M, Long CB, et al. Dynamics of cell-mediated immune responses to cytomegalovirus in pediatric transplantation recipients. Pediatr Transpl. 2012;16(1):18-28. https ://doi.org/10.1111/j.1399-3046.2011.01531.x.

131. Westall GP, Mifsud NA, Kotsimbos T. Linking CMV serostatus to episodes of CMV reactivation following lung transplantation by measuring CMV-specific CD8 + T-cell immunity. Am J Transpl. 2008;8(8):1749-54. https://doi.org/10.111 1/j.1600-6143.2008.02294.x.

132. Urschel S, Cremer S, Birnbaum J, et al. Lack of serologic immunity against vaccine-preventable diseases in children after thoracic transplantation. Transpl Int. 2010;23(6):619-27. https://doi. org/10.1111/j.1432-2277.2009.01030.x.

133. Kano H, Mizuta K, Sakakihara Y, et al. Efficacy and safety of immunization for pre- and post- liver transplant children. Transplantation. 2002;74(4):543-50.

134. L'Huillier AG, Wildhaber BE, Belli DC, et al. Successful serology-based intervention to increase protection against vaccine-preventable diseases in liver-transplanted children: a 19-yr review of the Swiss national reference center. Pediatr Transpl. 2012;16(1):50-7. https://doi.org/10.111 1/j.1399-3046.2011.01600.x.

135. Khan S, Erlichman J, Rand EB. Live virus immunization after orthotopic liver transplantation. Pediatr Transpl. 2006;10(1):7882. https://doi.org/10.1111/j.1399-3046.2005.00403.x.

136. Shinjoh M, Miyairi I, Hoshino K, et al. Effective and safe immunizations with live-attenuated vaccines for children after living donor liver transplantation. Vaccine. 2008;26(52):6859-63. https ://doi.org/10.1016/j.vaccine.2008.09.076.

137. Rand EB, McCarthy CA, Whitington PF. Measles vaccination after orthotopic liver transplantation. J Pediatr. 1993;123(1):87-9.

138. Verleden GM, Vos R, Van Raemdonck DE, et al. Acute liver failure due to Varicella zoster virus infection after lung transplantation: a case report. Transpl Proc. 2012;44(5):1457-9. https:// doi.org/10.1016/j.transproceed.2011.12.077.

139. Danziger-Isakov L, Kumar D. Practice ASTIDCo. Vaccination in solid organ transplantation. Am J Transpl. 2013;13(Suppl 4):311-7. https://doi.org/10.1111/ajt.12122.

140. Omer SB, Salmon DA, Orenstein WA, et al. Vaccine refusal, mandatory immunization, and the risks of vaccine-preventable diseases. N Engl J Med. 2009;360(19):1981-8. https://doi. org/10.1056/NEJMsa0806477.

141. Bavinger C, Bendavid E, Niehaus K, et al. Risk of cardiovascular disease from antiretroviral therapy for HIV: a systematic review. PLoS One. 2013;8(3):e59551. https://doi.org/10.1371/ journal.pone.0059551.

142. Markkula J, Hemming M, Vesikari T. Detection of vaccinederived rotavirus strains in nonimmunocompromised children up to 3-6 months after RotaTeq(R) vaccination. Pediatr Infect Dis J. 2015;34(3):296-8. https://doi.org/10.1097/inf.0000000000 000579.

143. Schuurmans MM, Isenring BD, Jungo C, et al. Clinical features and outcomes of influenza infections in lung transplant recipients: a single-season cohort study. Transpl Inf Dis. 2014;16(3):430-9. https://doi.org/10.1111/tid.12228.

144. World Health Organization. Recommended composition of influenza virus vaccines for use in the 2016-2017 northern hemisphere influenza season. Wkly Epidemiol Rec. 2016;91(10):121-32.

145. Baluch A, Humar A, Eurich D, et al. Randomized controlled trial of high-dose intradermal versus standard-dose intramuscular influenza vaccine in organ transplant recipients. Am J Transpl. 2013;13(4):1026-33. https://doi.org/10.1111/ajt.12149.

146. Manuel O, Humar A, Berutto C, et al. Low-dose intradermal versus intramuscular trivalent inactivated seasonal influenza vaccine in lung transplant recipients. J Heart Lung Transpl. 2011;30(6):679-84. https://doi.org/10.1016/j.healu n.2011.01.705.

147. Cordero E, Roca-Oporto C, Bulnes-Ramos A, et al. Two doses of inactivated influenza vaccine improve immune response in solid organ transplant recipients: results of TRANSGRIPE 1-2, a randomized controlled clinical trial. Clin Infect Dis. 2017;64(7):829_ 38. https://doi.org/10.1093/cid/ciw855.

148. Kumar D, Humar A, Plevneshi A, et al. Invasive pneumococcal disease in solid organ transplant recipients-10-year prospective population surveillance. Am J Transpl. 2007;7(5):1209-14. https ://doi.org/10.1111/j.1600-6143.2006.01705.x.

149. Miller E, Andrews NJ, Waight PA, et al. Herd immunity and serotype replacement 4 years after seven-valent pneumococcal conjugate vaccination in England and Wales: an observational cohort study. Lancet Infect Dis. 2011;11(10):760-8. https://doi. org/10.1016/s1473-3099(11)70090-1.

150. Huprikar S, Danziger-Isakov L, Ahn J, et al. Solid organ transplantation from hepatitis B virus-positive donors: consensus guidelines for recipient management. Am J Transpl. 2015;15(5):1162-72. https://doi.org/10.1111/ajt.13187.

151. Loinaz C, de Juanes JR, Gonzalez EM, et al. Hepatitis B vaccination results in 140 liver transplant recipients. Hepato-gastroenterology. 1997;44(13):235-8.

152. Kwak EJ, Julian K. Human papillomavirus infection in solid organ transplant recipients. Am J Transpl. 2009;9(Suppl 4):S151-60. https://doi.org/10.1111/j.1600-6143.2009.02906.x.

153. Deppisch C, Herrmann G, Graepler-Mainka U, et al. Gaseous nitric oxide to treat antibiotic resistant bacterial and fungal lung infections in patients with cystic fibrosis: a phase I clinical study. Infection. 2016;44(4):513-20. https://doi.org/10.1007/s1501 0-016-0879-x.

154. Howlin RP, Cathie K, Hall-Stoodley L, et al. Low-dose nitric oxide as targeted anti-biofilm adjunctive therapy to treat chronic pseudomonas aeruginosa infection in cystic fibrosis. Mol Ther. 2017;25(9):2104-16. https://doi.org/10.1016/j.ymthe .2017.06.021.

155. Yaacoby-Bianu K, Gur M, Toukan Y, et al. Compassionate nitric oxide adjuvant treatment of persistent mycobacterium infection in cystic fibrosis patients. Pediatr Infect Dis J. 2018;37(4):336-8. https://doi.org/10.1097/inf.0000000000001780.

156. Fang FC. Perspectives series: host/pathogen interactions. Mechanisms of nitric oxide-related antimicrobial activity. J Clin Investig. 1997;99(12):2818-25. https://doi.org/10.1172/jci119473.

157. Ghaffari A, Miller CC, McMullin B, et al. Potential application of gaseous nitric oxide as a topical antimicrobial agent. Nitric Oxide Biol Chem. 2006;14(1):21-9. https://doi.org/10.1016/j. niox.2005.08.003.

158. Hurford WE. Nitric oxide as a bactericidal agent: is the cure worse than the disease? Respir Care. 2005;50(11):1428-9.

159. Schairer DO, Chouake JS, Nosanchuk JD, et al. The potential of nitric oxide releasing therapies as antimicrobial agents. Virulence. 2012;3(3):271-9. https://doi.org/10.4161/viru.20328.

160. Clary G, Sasindran SJ, Nesbitt N, et al. Mycobacterium abscessus smooth and rough morphotypes form antimicrobial-tolerant biofilm phenotypes but are killed by acetic acid. Antimicrob Agents Chemother. 2018. https://doi.org/10.1128/aac.01782-17. 
161. Alegre M-L, Mannon RB, Mannon PJ. The microbiota, the immune system and the allograft. Am J Transpl. 2014;14(6):1236-48. https://doi.org/10.1111/ajt.12760.

162. Ursell LK, Metcalf JL, Parfrey LW, et al. Defining the human microbiome. Nutr Rev. 2012;70(Suppl 1):S38-44. https://doi.org /10.1111/j.1753-4887.2012.00493.x.

163. Cribbs SK, Beck JM. Microbiome in the pathogenesis of cystic fibrosis and lung transplant-related disease. Transl Res. 2017;179:84-96. https://doi.org/10.1016/j.trsl.2016.07.022.

164. Muhlebach MS, Zorn BT, Esther CR, et al. Initial acquisition and succession of the cystic fibrosis lung microbiome is associated with disease progression in infants and preschool children. PLoS Pathog. 2018;14(1):e1006798. https://doi.org/10.1371/ journal.ppat.1006798.

165. Stokell JR, Gharaibeh RZ, Hamp TJ, et al. Analysis of changes in diversity and abundance of the microbial community in a cystic fibrosis patient over a multiyear period. J Clin Microbiol. 2015;53(1):237-47. https://doi.org/10.1128/jcm.02555-14.

166. Cox MJ, Allgaier M, Taylor B, et al. Airway microbiota and pathogen abundance in age-stratified cystic fibrosis patients. PLoS One. 2010;5(6):e11044. https://doi.org/10.1371/journ al.pone.0011044.

167. Burke DG, Fouhy F, Harrison MJ, et al. The altered gut microbiota in adults with cystic fibrosis. BMC Microbiol. 2017;17(1):58. https://doi.org/10.1186/s12866-017-0968-8.
168. Duytschaever G, Huys G, Bekaert M, et al. Cross-sectional and longitudinal comparisons of the predominant fecal microbiota compositions of a group of pediatric patients with cystic fibrosis and their healthy siblings. Appl Environ Microbiol. 2011;77(22):8015-24. https://doi.org/10.1128/aem.05933-11.

169. Ju T, Shoblak Y, Gao Y, et al. Initial gut microbial composition as a key factor driving host response to antibiotic treatment, as exemplified by the presence or absence of commensal Escherichia coli. Appl Environ Microbiol. 2017. https://doi.org/10.1128/ aem.01107-17.

170. Mouraux S, Bernasconi E, Pattaroni C, et al. Airway microbiota signals anabolic and catabolic remodeling in the transplanted lung. J Allergy Clin Immunol. 2018;141(2):718-729.e7. https:// doi.org/10.1016/j.jaci.2017.06.022.

171. Charlson ES, Diamond JM, Bittinger K, et al. Lung-enriched organisms and aberrant bacterial and fungal respiratory microbiota after lung transplant. Am J Respir Crit Care Med. 2012;186(6):536-45. https://doi.org/10.1164/rccm.20120 4-0693OC.

172. Willner DL, Hugenholtz P, Yerkovich ST, et al. Reestablishment of recipient-associated microbiota in the lung allograft is linked to reduced risk of bronchiolitis obliterans syndrome. Am J Respir Crit Care Med. 2013;187(6):640-7. https://doi.org/10.1164/ rccm.201209-16800C. 